\title{
RELATÓRIO DAS ATIVIDADES REALIZADAS NAS "COMEMORAÇÕES DOS 170 ANOS DE FUNDAÇÃO DOS CURSOS JURÍDICOS NO BRASIL - (1827-1997) E DO SESQUICENTENÁRIO DE CASTRO ALVES".
}

Realização:

Faculdade de Direito da Universidade de São Paulo

Centro Acadêmico XI de Agosto

Apoio:

Ministério da Cultura

Pró-Reitoria de Cultura e Extensão Universitária USP

"Alternativas ao Neoliberalismo"

Roberto Freire - Senador pelo PPS/PE

Data: $\quad 08.08 .1997$ (11h00)

Local: Sala dos Estudantes

Júri Simulado - Caso José Rainha Júnior

Data: $\quad 08.08 .1997$ (15h00 às $22 \mathrm{~h} 00$ )

Local: Salão Nobre

Assinatura de Convênio entre Departamento Jurídico, C.A. XI de Agosto, Faculdade de Direito e Pró-Reitoria de Cultura e Extensão Universitária da Universidade de São Paulo.

Data: $\quad 11.08 .1997$ (9h00)

Local: Gabinete do Diretor

Cerimônia de Abertura:

Hino Nacional com a Banda da Polícia Militar.

- Presenças do Ministro da Cultura, Francisco Corrêa Weffort, do Secretário de Apoio à Cultura, José Álvaro Moises, do Reitor da Universidade de São Paulo, Flávio Fava de Moraes, do Pró-Reitor de Cultura e Extensão da Universidade de São Paulo, Jacques Marcovitch, do Diretor da Faculdade de Direito da 
Universidade de São Paulo, Álvaro Villaça Azevedo e do Presidente do C.A. XI de Agosto, Denis Fernando Mizne.

Data: $\quad 11.08 .1997(10 \mathrm{~h} 00)$

Local: Salão Nobre

"Castro Alves em São Paulo e na sua Faculdade de Direito"

(Comemorações do Sesquicentenário de Castro Alves)

Professor Rubens Limongi França (São Paulo)

Data: $\quad 11.08 .1997$

Ato pelo Desarmamento e Contra a Violência, promovido pelo C.A. XI de Agosto, em parceria com a OAB/SP, UNE, UEE, Comissão de Justiça e Paz, e outras entidades, com o apoio da Faculdade de Direito da Universidade de São Paulo.

Data: $\quad 11.08 .1997(11 \mathrm{~h} 00)$

Inauguração das placas do ex-presidente da República, Jânio da Silva Quadros, e do Eminente Político Ulysses Guimarães.

Data: $\quad 11.08 .1997(13 \mathrm{~h} 00)$

Local: Pátio das Arcadas

Coquetel de Abertura da "II Semana de Arte nas Arcadas" (com o apoio da ECA/USP), com destaque a Domenico Calabroni e Aldemir Martins.

Data: $\quad 11.08 .1997(17$ h00)

Apresentação do Grupo XI de Agosto (Coralusp);

Declamação do ator e ex-aluno da Faculdade de Direito, Paulo Autran, recitando poesias de Castro Alves (Comemorações do Sesquicentenário de Castro Alves). (não-compareceu).

"Democracia Representativa: mitos, crises e paradigmas"

Olívio Dutra ex-prefeito de Porto Alegre;

Miguel Reale Jr. - professor da FDUSP

Data: $\quad 12.08 .1997(10 \mathrm{~h} 00)$

Local: Sala dos Estudantes 
Entrega do Prêmio XI de Agosto conferido pelo C.A. XI de Agosto ao Professor Emérito Goffredo da Silva Telles Júnior.

Apresentação dos Jograis da Academia Associação dos Ex-Alunos da Faculdade de Direito - Homenagem de José Carlos Dias.

Apresentação da Orquestra Jazz Sinfônica do Estado de São Paulo, da Secretaria de Estado de Cultura do Município de São Paulo.

Data: $\quad 12.08 .1997(12 \mathrm{~h} 00)$

Local: Pátio das Arcadas

"Instrumentos de Democracia Participativa"

- Luiza Erundina - ex-prefeita de São Paulo

- Antonio Pallocci presidente estadual do PT

- Maria Inês Bierrenbach presidente do CONDEPE

Data: $\quad 12.08 .1997(19 \mathrm{~h} 00)$

"Comemorações do Sesquicentenário de Castro Alves"

Data: $\quad 12.08 .1997$

Local: Auditório do Prédio Anexo

"As Imagens Cósmicas na Poesia de Castro Alves"

Professor Cesar Leal (Recife)

Data: 12.08 .1997 (19h00)

Local: Auditório Prédio Anexo

"Castro Alves e sua Poesia Social"

Professor Edivaldo Boaventura (Salvador)

Data: $\quad$ 12.08.1997 (20h00)

Local: Auditório Prédio Anexo

"O fenômeno da política não-governamental e suas relações com o Estado"

Belisário dos Santos Jr. secretário Estadual de Justiça e Defesa da Cidadania

- Roberto Romano professor da UNICAMP

Data: $\quad$ 13.08.1997 (19h00) 
"Castro Alves e a Negritude"

Professor Antonio Junqueira de Azevedo (São Paulo)

Data: $\quad$ 13.08.1997 (10h00)

Local: Auditório do Prédio Anexo

Final do Concurso de Declamação de Poesias de Castro Alves.

Vencedora: Juliana Battistella (aluna do $5^{\circ}$ ano).

Data: $\quad 13.08 .1997$

Encerramento da Semana do XI

Data: $\quad 15.08 .1997(11 \mathrm{~h} 00)$

Local: Salão Nobre

"Separação de Poderes e Consolidação da Democracia no Brasil"

Ministro José Celso de Mello Filho, Presidente do Supremo Tribunal Federal

Iris Rezende Ministro da Justiça

- Michel Temer - presidente da Câmara dos Deputados

Local: Sala dos Estudantes

"Meus Tempos de Faculdade"

- Aloísio Nunes Ferreira Filho presidente do C.A. XI em 1967 e Deputado Federal pelo PMDB/SP

Marcos Mendonça secretário Estadual da Cultura

Almino Affonso Orador do XI em 1952 e Deputado Federal pelo PSDB/SP

Data: $\quad 18.08 .1997$

Local: Sala dos Estudantes

"Meus Tempos de Faculdade"

Fábio Feldman vice-presidente do C.A. XI em 1979 e secretário Estadual do Meio Ambiente.

Data: $\quad$ 19.08.1997

Local: Sala dos Estudantes 
Solenidade de entrega pública do IV Volume da edição "fac símile" das Actas das Sessões da Congregação da Academia de Direito do Largo São Francisco, entre os anos de 1897 e 1906.

Data: $\quad$ 10.12.1997

Local: Sala da Congregação 